\title{
Design of a Load Torque Based Control Strategy for Improving Electric Tractor Motor Energy Conversion Efficiency
}

\author{
Mengnan Liu, ${ }^{1}$ Liyou $\mathrm{Xu}^{2}{ }^{2}$ and Zhili Zhou ${ }^{2}$ \\ ${ }^{1}$ School of Mechanical and Precision Instrument Engineering, Xian University of Technology, No. 5, \\ Jinhua South Road, Beilin District, Xi'an 710048, China \\ ${ }^{2}$ Vehicle \& Transportation Engineering Institute, Henan University of Science and Technology, No. 48, \\ Xiyuan Road, Jianxi District, Luoyang 471003, China
}

Correspondence should be addressed to Mengnan Liu; liumengnan27@163.com

Received 12 January 2016; Revised 23 March 2016; Accepted 31 March 2016

Academic Editor: Luis J. Yebra

Copyright (C) 2016 Mengnan Liu et al. This is an open access article distributed under the Creative Commons Attribution License, which permits unrestricted use, distribution, and reproduction in any medium, provided the original work is properly cited.

In order to improve the electrical conversion efficiency of an electric tractor motor, a load torque based control strategy (LTCS) is designed in this paper by using a particle swarm optimization algorithm (PSO). By mathematically modeling electric-mechanical performance and theoretical energy waste of the electric motor, as well as the transmission characteristics of the drivetrain, the objective function, control relationship, and analytical platform are established. Torque and rotation speed of the motor's output shaft are defined as manipulated variables. LTCS searches the working points corresponding to the best energy conversion efficiency via PSO to control the running status of the electric motor and uses logic and fuzzy rules to fit the search initialization for load torque fluctuation. After using different plowing forces to imitate all the common tillage forces, the simulation of traction experiment is conducted, which proves that LTCS can make the tractor use electrical power efficiently and maintain agricultural applicability on farmland conditions. It provides a novel method of fabricating a more efficient electric motor used in the traction of an off-road vehicle.

\section{Introduction}

A potential development trend of farming power is that sustainable energies, such as electricity and biodiesel, will gradually and eventually replace the nonrenewable fossil fuels. An electric tractor is one of the transformation directions. Carlini et al. presented a series hybrid electric powertrain for a small crawler tractor used for logging in forests. It reached a 30\% increase in fuel economy and better ecological features in comparison with the traditional tractor [1]. Florentsev et al. developed an electromechanical drive train for a $300 \mathrm{hp}$ class tractor. The plowing production was $2 \%$ higher compared to the traditional tractor with power-shift drive train, while fuel consumption was lower by $18 \%$ [2]. Based on our research in the static analysis of a $180 \mathrm{hp}$ class electric tractor, the tractive efficiency average increased by $2.98 \%$ [3]. These achievements show that the electric tractor has the structural advantage in energy conservation. However, in its drivetrain, an electric motor acts as the engine whose energy efficiency tightly links to the running status. In fact, owing to the diversity of farming works, complexity of soil characteristics, and variation of driving resistance, the load torque of the drive wheel changes frequently and suddenly when tractors work on the farm [4]. Consequently, the motor cannot always maintain high-level energy conversion efficiency. Focused on this problem, control strategies designed for promoting the energy efficiency of electric motors meet the developing requirement of resource-saving and environment friendly agricultural machinery technology.

Related studies have been performed for improving the energy conversion economy of electric vehicles. By analyzing five types of control strategies used in high-power vehicles, Garcia et al. proved that the equivalent fuel consumption minimization strategy had better applicability [5]. Via comparison with a batch Genetic Algorithm-based optimization, Sorrentino et al. designed a rule-based control strategy for on-board energy management of series hybrid vehicles, which could improve the fuel economy of hybrid solar 
vehicles [6]. However, researches like these only refer to the management optimization of energy systems that included the battery, the electric generator powered by an internal combustion engine (ICE), and other assistance energy sources. They also do not take electric energy-using device into consideration, which means such control strategies are not suitable for the energy conversion economy improvement of the electric vehicle with a simple energy system, such as a purely electric vehicle. To account for this, Shabbir and Evangelou investigated a real-time control strategy, which uses a control map computed off-line to maximize the drivetrain efficiency of hybrid electric vehicles [7]. Another control strategy was proposed by Osornio-Correa et al. based on the heuristic map created to analyze the restrictions and benefits of using either of the on-board power plants under different driving conditions for maximum energy economy of a parallel hybrid electric vehicle [8]. However, those researches lack discussion of how to improve the EM energy conversion efficiency. In addition, the establishment of a control map requires extensive experimental data as a practical foundation (which means it would be difficult to use in product development phases of the vehicle). Wu et al. optimized principal parameters of both the powertrain and the control strategy using a PSO and achieved an acceptable result. However, the optimization of electric motor control strategy was also ignored [9]. Elwer et al. optimized the scaling factors of a fuzzy controller used for enhancing the rapidity, accuracy, and robustness of the electric vehicle motor [10]. However, the controller is not helpful in the improvement of motor energy conversion efficiency. By using an adaptive network in a fuzzy inference system optimization algorithm, the strategy put forth by Qian et al. made the ICE of series hybrid electric vehicle work with high energy conversion efficiency [11]. Unfortunately, in a series hybrid electric vehicle, ICE is mechanically decoupled to the drive wheel, and its mechanical power output is not constrained by load characteristic. Therefore, the control strategy cannot be imitatively used in traction motor. In an ordinary electric drivetrain or pure electric vehicle, an electric motor works as the sole energy conversion device, so the energy conversion efficiency of the drivetrain (or the vehicle) is only promoted by means of controlling the working state of the electric motor. Nevertheless, the energy conversion efficiency of the electric motor tightly couples with its rotate speed and torque, which are also dependent upon the actual driving demand of the vehicle. For the road vehicle, complex and frequently changing road condition means it is impractical that control of the mechanical characteristics of the electric motor is dependent upon its energy conversion efficiency, while neglecting the speed requirements of safety, practicability, and traffic laws. However, in the agricultural conditions of the tractor, the frequent change of speed is not required, and the load force is normally stable. Therefore, we can try to control the electric motor's running state for improved energy conversion efficiency. In summary, research on an efficient control strategy for an electric tractor motor is both needed and innovative.

This paper begins with establishing the mathematical model that describes the electric-mechanical performance

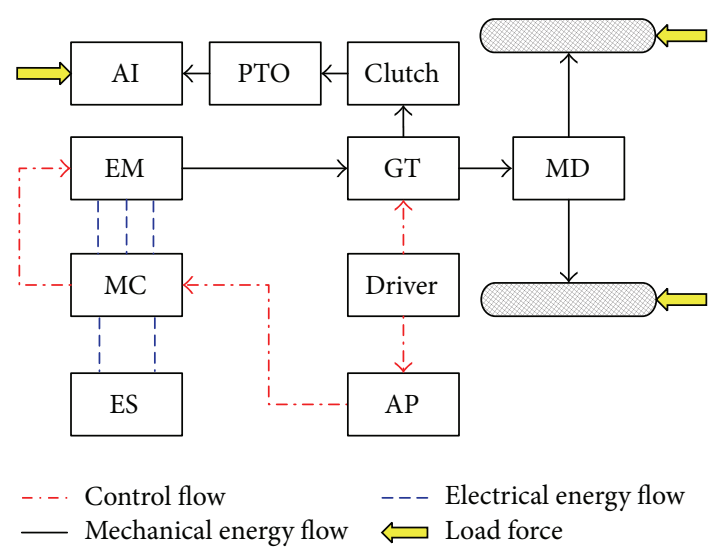

Figure 1: Scheme of an electric tractor's drivetrain.

and theoretical energy consumption of the electric motor, as well as the transmission characteristics of the electric tractor. Then, it introduces the design of LTCS and how it can control the electric motor to maintain high energy conversion efficiency. Finally, simulation of the traction experiment is conducted to verify the effect and agricultural applicability of LTCS.

\section{Mathematical Model}

2.1. Introduction of the Electric Tractor Drivetrain. Although the electric tractor shares many common structural features with the common electric vehicle, there are some significant differences between the two drivetrains. Particularly, the electric vehicle layout is organized as shown in Figure 1. The electric tractor drivetrain is powered by the energy system (ES). The ES can contain the storage battery in a pure electric tractor or the ICE, generator, battery, super-capacitor, and so forth in a hybrid electric tractor. The electric motor (EM) provides the mechanical power for the drive wheel and power take-off shaft (PTO). PTO joints with the EM via the clutch. When the tractor only drives the agricultural implement (AI), the clutch decouples the mechanical connection between the PTO and the drive wheel, which makes the mechanical power flows of them be independent of each other. The gearbox transmission (GT) can transform the dynamic power performance field of the drive wheel via the gear shifting operation of driver. And the GT directly transmits the mechanical power to PTO, which can make the rotate speed of PTO match with either the rotate speed of the EM or the forward velocity of the electric tractor. The main drive (MD) acts as the differential mechanism and final reducer of the transmission system. By stepping on the accelerator pedal (AP), the driver can control the EM through electrical adjustment of the motor controller (MC). Generally, there are two types of load force exerted upon the electric tractor: one is driving force and the other is tilling force.

2.2. Electric-Mechanical Performance of the Electric Motor (EM). According to the previous research, the EM is 
a brushless direct current motor (BLDC) [3]. The voltage per phase can be expressed by

$$
\begin{aligned}
& U_{\mathrm{a}}=R_{\mathrm{s}} I_{\mathrm{a}}+\left[\frac{\left(L_{\mathrm{a}}-L_{\mathrm{m}}\right) d I_{\mathrm{a}}}{d t}\right]+e_{\mathrm{a}}, \\
& U_{\mathrm{b}}=R_{\mathrm{s}} I_{\mathrm{b}}+\left[\frac{\left(L_{\mathrm{b}}-L_{\mathrm{m}}\right) d I_{\mathrm{b}}}{d t}\right]+e_{\mathrm{b}}, \\
& U_{\mathrm{c}}=R_{\mathrm{s}} I_{\mathrm{c}}+\left[\frac{\left(L_{\mathrm{c}}-L_{\mathrm{m}}\right) d I_{\mathrm{c}}}{d t}\right]+e_{\mathrm{c}} .
\end{aligned}
$$

After equivalent transformation, the electromechanical characteristics of BLDC can be described by the following equations [12]:

$$
\begin{aligned}
U_{\mathrm{t}} & =R_{\mathrm{s}} I_{\mathrm{s}}+\left[\frac{\left(L_{\mathrm{n}}-L_{\mathrm{m}}\right) d I_{\mathrm{s}}}{d t}\right]+e_{\mathrm{s}}, \\
L_{\mathrm{s}} & =L_{\mathrm{n}}-L_{\mathrm{m}}, \\
e_{\mathrm{s}} & =k_{E} \omega_{\mathrm{r}} .
\end{aligned}
$$

The electromagnetic torque of BLDC, $T_{\mathrm{e}}$, can be obtained as follows:

$$
\begin{aligned}
& T_{\mathrm{e}}=\frac{9.55\left(e_{\mathrm{a}} I_{\mathrm{a}}+e_{\mathrm{b}} I_{\mathrm{b}}+e_{\mathrm{c}} I_{\mathrm{c}}\right)}{\omega_{\mathrm{r}}}=\frac{9.55 e_{\mathrm{s}} I_{\mathrm{s}}}{\omega_{\mathrm{r}}}, \\
& T_{\mathrm{e}}=k_{T} I_{\mathrm{s}} .
\end{aligned}
$$

Depending on (3) and (4), the torque constant, $k_{T}$, is equal to back EMF constant, $k_{E}$, after the dimension change.

When BLDC is working on traction, the electromagnetic torque of the motor can also be described by

$$
T_{\mathrm{e}}=T_{\mathrm{L}}+J \frac{d \omega_{\mathrm{r}}}{d t}+V \omega_{\mathrm{r}}
$$

Based on the Laplace transform of (1)-(5), the electricmechanical performance of BLDC can be expressed by the following transfer function:

$$
\begin{aligned}
\omega_{\mathrm{r}}(s)= & \frac{k_{T}}{\left(R_{\mathrm{s}}+s L_{\mathrm{s}}\right)(s J+V)+k_{E} k_{T}} U_{\mathrm{t}}(s) \\
& -\frac{R_{\mathrm{s}}+s L_{\mathrm{s}}}{\left(R_{\mathrm{s}}+s L_{\mathrm{s}}\right)(s J+V)+k_{E} k_{T}} T_{\mathrm{L}}(s) .
\end{aligned}
$$

Consequently, the steady state characteristic can be established:

$$
\omega_{\mathrm{r}}=\frac{k_{T}}{R_{\mathrm{s}} V+k_{E} k_{T}} U_{\mathrm{t}}-\frac{R_{\mathrm{s}}}{R_{\mathrm{s}} V+k_{E} k_{T}} T_{\mathrm{L}} .
$$

According to (4), (6), and (7), the mechanical performance of the EM can be linked to the controllable electric parameter.

2.3. Energy Consumption Model of the EM. When the EM is running, electric power loss contains copper loss, icon loss, mechanical loss, and constant power used for driving the MC.
Copper loss, $P_{\mathfrak{c}}$, is the prime waste of the BLDC. This is due to the fact that the stator winding impedance converts the electric power to the thermal dissipated to the surroundings. It can be obtained as follows [13]:

$$
P_{\mathrm{c}}=I_{\mathrm{s}}^{2} R_{\mathrm{s}}
$$

According to (4), the value of the current is directly proportional to the value of electromagnetic torque. Thus, we can use a coefficient, $k_{\mathrm{c}}$, to describe the relationship between the copper loss and the electromagnetic torque. The copper loss can be rewritten as follows:

$$
P_{\mathrm{c}}=k_{\mathrm{c}} T_{\mathrm{e}}^{2} .
$$

The copper loss coefficient, $k_{\mathrm{c}}$, can be calculated by

$$
k_{\mathrm{c}}=\frac{R_{\mathrm{s}}}{k_{T}^{2}} .
$$

Icon loss power, $P_{\mathrm{i}}$, mainly contains magnetic hysteresis loss and current loss, and its mechanisms are complex and changing. It mainly depends on the speed of rotor and is described by

$$
P_{\mathrm{i}}=k_{\mathrm{i}} \omega_{\mathrm{r}} .
$$

In the BLDC, $k_{\mathrm{i}}$ can be approximately seen as a constant and can be measured by an experimental method.

The mechanical loss $P_{\mathrm{M}}$, output from the rotor, is largely wasted on air resistance. It can be obtained by

$$
P_{\mathrm{M}}=k_{\mathrm{w}} \omega_{\mathrm{r}}^{3} .
$$

The mechanical power output and total power input of the electric motor can be described by the following equations:

$$
\begin{aligned}
P_{\text {out }} & =\frac{T_{\mathrm{L}} \omega_{\mathrm{r}}}{9550} \\
P_{\text {in }} & =P_{\text {out }}+P_{\mathrm{c}}+P_{\mathrm{i}}+P_{\mathrm{M}}+C .
\end{aligned}
$$

According to (7)-(13), the electric conversion energy efficiency, $\eta_{\mathrm{m}}$, may be established by

$$
\begin{aligned}
\eta_{\mathrm{m}} & =\frac{P_{\text {out }}}{P_{\text {in }}} \\
& =\frac{T_{\mathrm{L}} \omega_{\mathrm{r}}}{T_{\mathrm{L}} \omega_{\mathrm{r}}+9550\left[k_{\mathrm{c}} T_{\mathrm{e}}^{2}+\left(k_{\mathrm{i}}+k_{\mathrm{w}} \omega_{\mathrm{r}}^{2}\right) \omega_{\mathrm{r}}+C\right]} .
\end{aligned}
$$

According to (14), which is the objective function of PSO searching, the theoretical relation of EM energy conversion efficiency to the mechanical performance can be established.

2.4. Transmission Characteristics of the Drivetrain. When the electric tractor works in the farm, the torque output of the EM distributes to the driving wheel and PTO and overcomes the driving and working resistance, respectively. The torque coupling relationship between the electric motor 
shaft, driving wheel, and PTO can be obtained by applying the following equations:

$$
\begin{aligned}
T_{\mathrm{L}} \omega_{\mathrm{r}} & =\frac{T_{\mathrm{TN}} \omega_{\mathrm{TN}}}{\eta_{\mathrm{g}} \eta_{0}}+\frac{T_{\mathrm{w}} \omega_{\mathrm{w}}}{\eta_{\mathrm{g}}^{\prime} \eta_{\mathrm{a}}}, \\
T_{\mathrm{L}} & =\frac{T_{\mathrm{TN}}}{i_{\mathrm{g}} i_{0} \eta_{\mathrm{g}} \eta_{0}}+\frac{T_{\mathrm{w}}}{i_{\mathrm{g}}^{\prime} i_{\mathrm{a}} \eta_{\mathrm{g}}^{\prime} \eta_{\mathrm{a}}}, \\
\omega_{\mathrm{r}} & =\omega_{\mathrm{TN}} i_{\mathrm{g}} i_{0}=\omega_{\mathrm{w}} i_{\mathrm{g}}^{\prime} i_{\mathrm{a}} .
\end{aligned}
$$

When the tractor plows, the force balance of the drivetrain can be described by the following equations:

$$
\begin{aligned}
F_{\mathrm{TN}} & =F_{\mathrm{g}}+F_{\mathrm{f}}+F_{\mathrm{p}}+F_{\mathrm{Af}}+F_{\mathrm{i}}, \\
F_{\mathrm{TN}} & =\frac{T_{\mathrm{TN}}}{1000 r_{\mathrm{TN}}}, \\
F_{\mathrm{g}} & =Z b_{1} h_{\mathrm{k}} k .
\end{aligned}
$$
follows:

Driving speed and tractive force can be described as

$$
\begin{aligned}
v & =0.377 \frac{r \omega_{\mathrm{r}} \eta_{\delta}}{i_{\mathrm{g}} i_{0}}, \\
F_{\mathrm{T}} & =F_{\mathrm{TN}} \eta_{\mathrm{T}}, \\
\eta_{\mathrm{T}} & =\eta_{\mathrm{c}} \eta_{\mathrm{f}} \eta_{\delta} .
\end{aligned}
$$

According to (15)-(17), the relationship between load and mechanical output of the EM can be expressed.

\section{Design of Load Torque Based Control Strategy (LTCS)}

3.1. Particle Swarm Optimization Algorithm (PSO) Introduction. In comparison with classical optimization methods, PSO is an efficient range-searching algorithm. By selecting the search threshold, the population behavior can be restricted to only running under working conditions and practical requirements. It is a helpful advantage to ensure that the control parameters produced by PSO conform to the speed and torque requirement of farming. Moreover, PSO can deal with nonsmooth, noncontinuous, and nondifferentiable functions simply with objective function information. Compared with other intelligence algorithms such as the Genetic Algorithm, there is one simple operator: velocity calculation in the PSO. Using the simpler algorithm means shorter computing time, less memory, and improved robustness [14]. Therefore, PSO is chosen here as the primary algorithm of LTCS.

By means of simulating bird flock preying behavior, particle swarm optimization used widely in the engineering field has the advantage of high robustness and low complexity [15]. In a searching space, the particles population, which contains $n$ particles, can be built as $X=\left(X_{1}, X_{2}, \ldots, X_{n}\right)$. The $i$ th particle is a vector with $m$ dimensionalities and can be built as $X_{i}=\left(X_{i 1}, X_{i 2}, \ldots, X_{i m}\right)^{T}$ to express the position of this particle, namely, a potential solution of the objective function. The fitness values of each $X_{i}$ may be calculated by the objective function. The speed of $X_{i}$ can be built as $V_{i}=\left(V_{i 1}, V_{i 2}, \ldots, V_{i n}\right)^{T}$, the individual best solution is $Y_{i}=\left(Y_{i 1}, Y_{i 2}, \ldots, Y_{i n}\right)^{T}$, and the swarm optimal solution is $Y_{g}=\left(Y_{g 1}, Y_{g 2}, \ldots, Y_{g n}\right)^{T}$. During the iterative process, every particle of the swarm uses its $Y_{i}$ and $Y_{g}$ to update the $V_{i}$ and $X_{i}$, which can be described as follows:

$$
\begin{aligned}
& V_{i d}^{\gamma+1}=\varepsilon V_{i d}^{\gamma}+c_{1} R_{1}\left(Y_{i d}^{\gamma}-X_{i d}^{\gamma}\right)+c_{2} R_{2}\left(Y_{g d}^{\gamma}-X_{i d}^{\gamma}\right), \\
& X_{i d}^{\gamma+1}=X_{i d}^{\gamma}+V_{i d}^{\gamma+1},
\end{aligned}
$$

where $d=1,2, \ldots, n ; i=1,2, \ldots, m$; and $R_{1}$ and $R_{2}$ are random numbers in $[0,1]$.

3.2. Working Characteristic. The 1804 series hybrid electric tractor was selected as the study object of this paper in a project designed by taking the YTO-1804 as a prototype [3]. Its drivetrain conforms to the description in Figure 1, and the speed-traction force performance curve is built in Figure 2.

When an 1804 hybrid works under heavy load gear or moderate load gear, the relationship between the driving speed and the traction force could be described by

$$
\frac{d F_{\mathrm{T}}}{d v}>\frac{d v}{d F_{\mathrm{T}}}
$$

When the tractor works under the light load gear or transport gear, the relationship can be described by the following equation:

$$
\begin{aligned}
& \frac{d v}{d F_{\mathrm{T}}} \approx \frac{d F_{\mathrm{T}}}{d v}, \\
& \frac{d F_{\mathrm{T}}}{d v}<\frac{d v}{d F_{\mathrm{T}}} .
\end{aligned}
$$

Since the 1804 hybrid always tills with a stable speed and main farm works are done by using heavy, moderate, and light load gear, meeting the requirement of the traction force is more important than meeting the requirement of the speed. Additionally, the control result can match the change of traction force well, and $T_{\mathrm{L}}$ and $\omega_{\mathrm{r}}$ are, respectively, defined as the independent variable and dependent variable of the PSO.

3.3. Control Strategy. Control function of the LTCS in the vehicle is shown in Figure 3. Compared with the electric tractor in Figure 1, the LTCS is added between the driver and the MC. Two input signals, which are, respectively, acquired from the position sensor on the accelerator pedal (AP) and the shift lever, are deduced and calculated by LTCS. Afterward, based on internal rules, LTCS provides control signals to the MC and energy system (ES) to control the running status of the EM.

When the position sensor measures the depth of AP, load torque can be calculated by

$$
T_{\mathrm{L}}=\frac{B-A \cdot N}{A \cdot(1-N)} \cdot T_{\max } .
$$




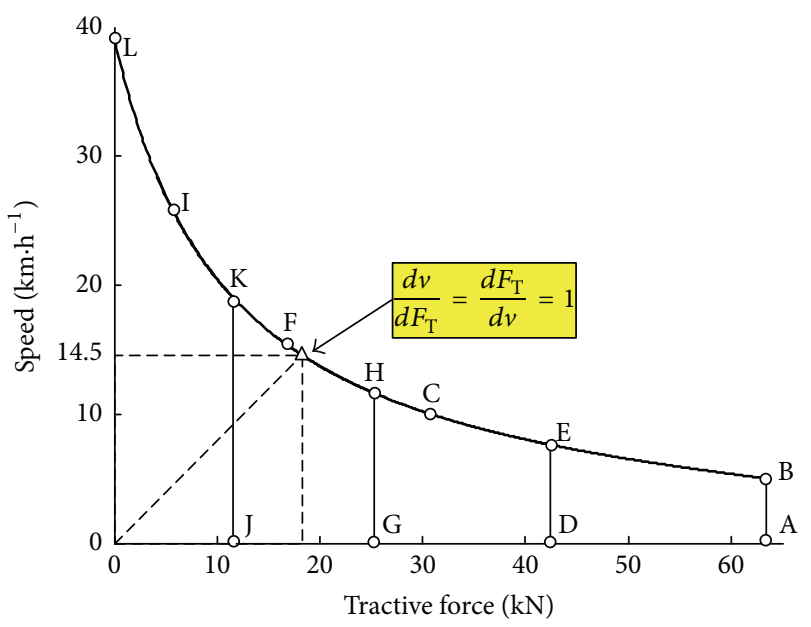
A-B-C Heavy load gear
G-H-I Light load gear
D-E-F Moderate load gear
J-K-L Transport gear

FIGURE 2: Speed-traction force performance curve of the 1804 series hybrid electric tractor.

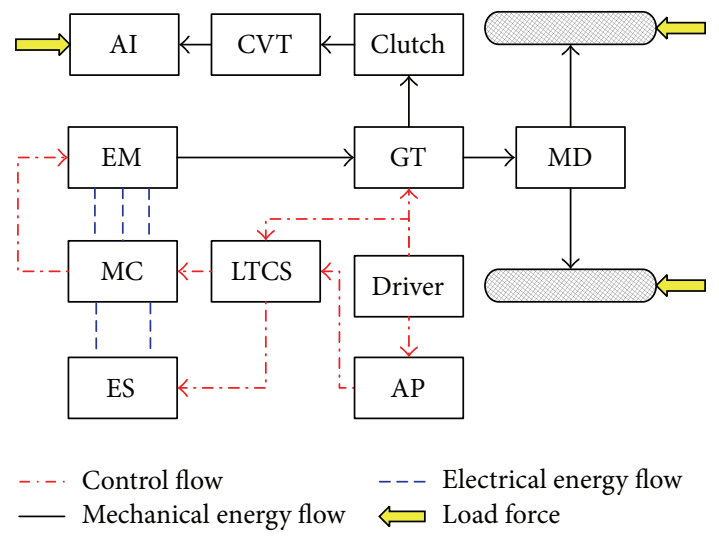

FIGURE 3: Schematic representation of the control function for the electric drivetrain.

During every sampling time, the internal task actions of LTCS are built in Figure 4, which includes two parts. One is the search process of the best energy-using working point, and the other is the timely control of the search process initialization.

The best working point $\left(\omega_{\mathrm{r}}^{\prime}, T_{\mathrm{L}}^{\prime}\right)$ that corresponds to the best electric energy efficiency of the drive motor is selected as the searching target of the PSO searching process. Because $T_{\mathrm{L}}^{\prime}$ should be greater than $T_{\mathrm{L}}$, the enclosure space $\left[T_{\mathrm{L}}, T_{\mathrm{L}}+\mathrm{Q}\right]$ is defined as the constraint. $Q$ is the adjustment torque.

After every initialization signal, the search process runs only once. Via (4) and (6), the searched best working point was used as the control parameter of the torque based current feedback control of the MC and the DC-AC converter of the energy system (ES) to, respectively, control the expected phase current and input voltage until the next initialization occurs, which follows these rules:
TABLE 1: Fuzzy rules to infer initialization.

\begin{tabular}{lccc}
\hline Deeping rate & \multicolumn{3}{c}{ Footplate depth } \\
& $\mathrm{S}$ & $\mathrm{M}$ & $\mathrm{B}$ \\
\hline$-\mathrm{B}$ & INIT & INIT & INIT \\
$-\mathrm{M}$ & HOLD & INIT & INIT \\
$\mathrm{S}$ & HOLD & HOLD & HOLD \\
$+\mathrm{M}$ & HOLD & INIT & INIT \\
$+\mathrm{B}$ & INIT & INIT & INIT \\
\hline
\end{tabular}

(1) In every sampling step, the initialization signals sent by the time trigger and load torque controller are synchronous and mutually independent. When the initialization is triggered, the search process and following control process occurred immediately.

(2) Using the sampling step as the period, the time trigger periodically sends the initialization signal. It is used to deal with the accumulation of smaller AP position changes, which cannot trigger the initialization signal of the load torque controller during every period.

(3) In every period, the initialization can also be controlled by the torque controller, which judges the load torque changing status. If the load change that occurred during this period is large enough, the PSO searching is initialized immediately.

3.4. The Design of Load Torque Controller. The load change degree is judged by the gearshift and footplate positions, which can be measured by the gear sensor and the AP position sensor.

Shifting gears is an operation greatly affected by the subjective intention of the driver. In other words, when the tractor meets visible topographic changes or the working type changes, where the load torque will likely experience a significant change, the driver usually shifts the gear. Logical algorithms are used to process the signal of the gearshift position. If the driver shifts the gear (which means the load torque condition change is large enough), the controller sends the initialization signal.

Under any gear, the driver can estimate the load force situation by viewing the tachometer reading. When the AP position is stable, changing the tachometer reading means that the force balance on the EM shaft has been broken. The driver should adjust the AP depth based on the change trend in the tachometer reading until the tractor speed is similar to what it was previously. A fuzzy controller is designed to deal with the AP signal, inferring the change degree of working condition and providing the initialization signal.

Wang et al. discussed the fuzzy rules that reflect the relationship between diver intention and AP operation [16]. Based on that, two of the fuzzy rules used for deducing the initialization of LTCS are shown here in Table 1.

The membership functions that belong to the footplate depth, the footplate deepening rate, and the collection mode are described by Figures 5-7.

In the case of the footplate depth, it has three chosen membership functions: S, small depth; M, moderate depth; and $\mathrm{B}$, big depth. They cover the full range of footplate 


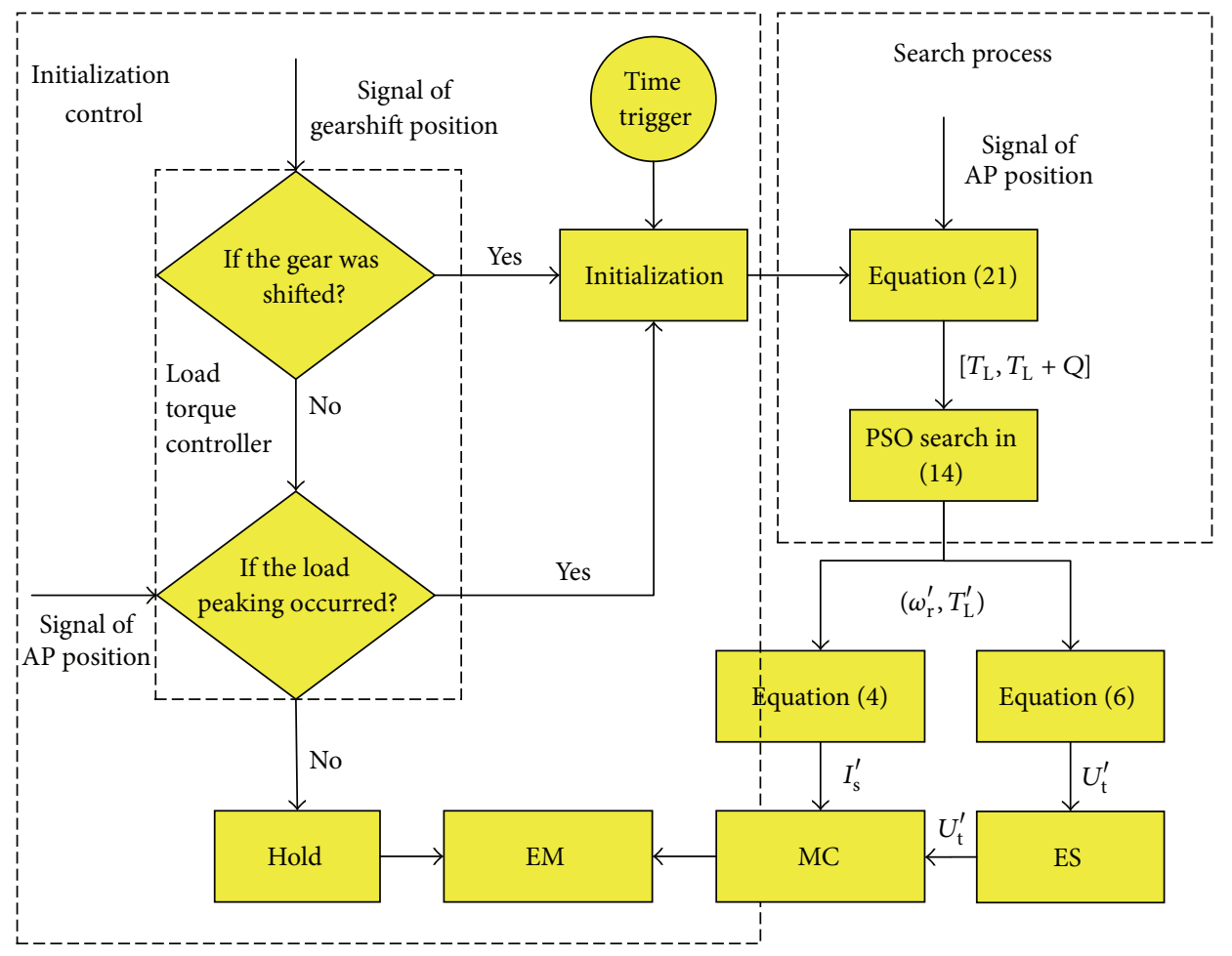

FIGURE 4: Schematic description of internal task actions within the LTCS.

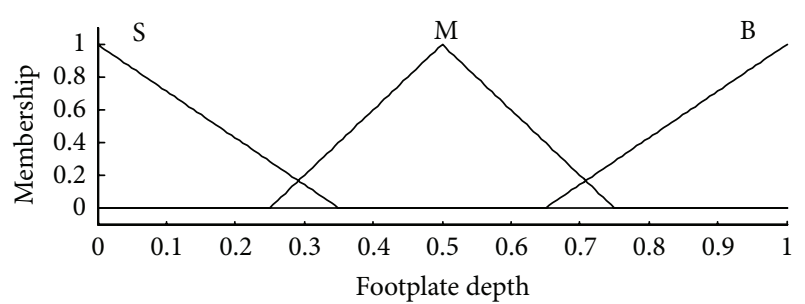

Figure 5: Membership functions of the footplate depth.

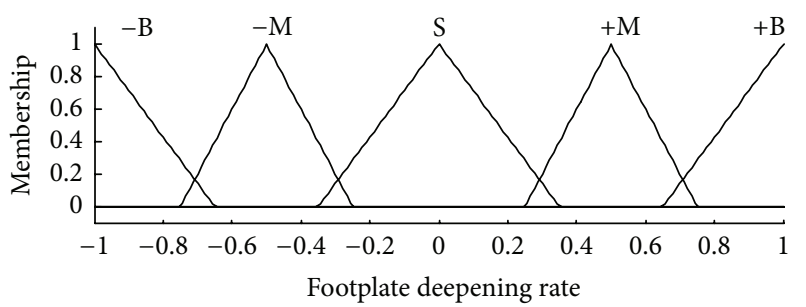

FIGURE 6: Membership functions of the footplate deepening rate.

depth. When the AP controls BLDC, its control function is equivalent to the voltage control process of the potentiometer. For the torque control of BLDC, the torque controlled by $\mathrm{AP}$ is normally proportional to the expected electric current, so the footplate depth membership functions are equally distributed. To transform the real domain into fuzzy domain scope $[0,1]$, the quantization factor of footplate depth, $\varepsilon_{\mathrm{d}}$, is calculated by

$$
\varepsilon_{\mathrm{d}}=A(1-N)
$$

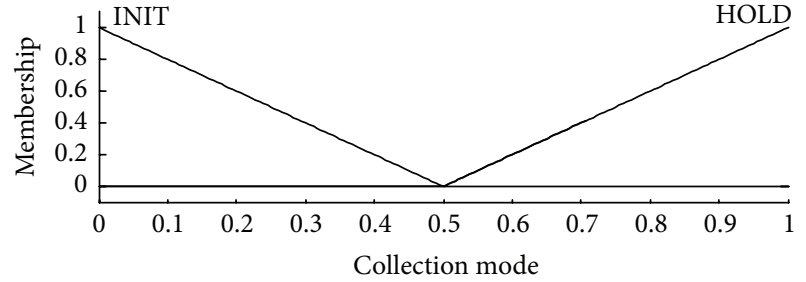

FIGURE 7: Membership functions of the collection mode.

In the case of the footplate deepening rate, five membership functions are considered: $S$, small change rate; $+M$, moderate deepening rate; $-\mathrm{M}$, moderate returning rate; $+\mathrm{B}$, big deepening rate; and $-\mathrm{B}$, big returning rate. When the tractor speed increases with an unchanged AP position, which means the load torque reduces, the driver may return the pedal until the speed changes back and vice versa. Thus, the formulation of footplate deepening rate membership functions should contain this case. The quantization factor of footplate deepening rate, $\varepsilon_{\mathrm{dr}}$, is calculated by

$$
\varepsilon_{\mathrm{dr}}=\frac{A(1-N)}{t_{\mathrm{r}}} .
$$

Depending on the test of McGehee et al. [17], $t_{\mathrm{r}}$ can be set as $1.28 \mathrm{~s}$.

Regarding the output variables, the collection mode contains two membership functions: INIT, the initialization of LTCS, and HOLD, nothing else changing in the load torque control process. Because the opposition between 


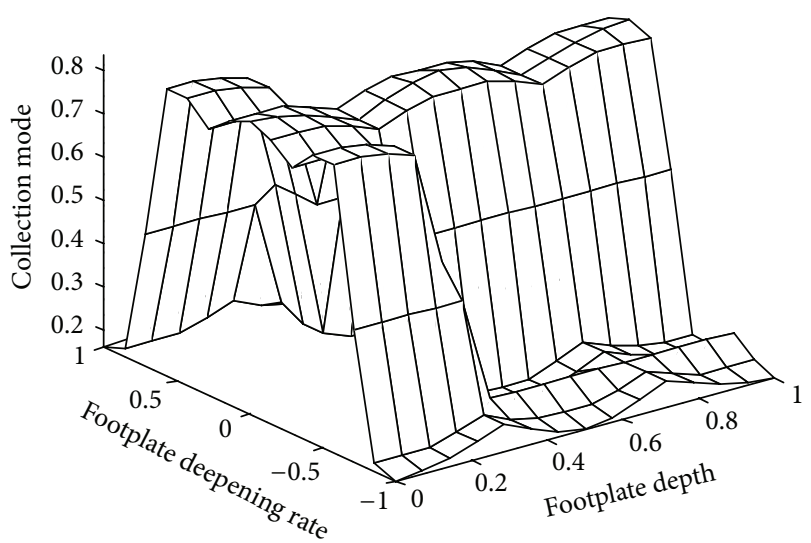

Figure 8: Fuzzy surface.

initialization and hold operations is definite and complete, their fuzzy domains are complementary.

Surface of the fuzzy rules can be viewed in Figure 8.

\section{Simulation of the Traction Experiment}

4.1. Parameters and Conditions of the Simulation. The simulation of the traction experiment is designed as a backward type. Working conditions, which act as the input of the simulation model, are required to contain all the common working resistances of the 1804 hybrid tractor. According to the common soil conditions of the Northeast China region, the rolling resistance coefficient, $f$, is 0.1 , the adhesion coefficient is 0.7 , and the clayed ground, whose soil specific resistances randomly changed from 0.007 to 0.01 , is tilled. Parameters of the plowing resistances, which imitate resistances of common working conditions, are expressed in Table 2.

The working condition in the simulation can be described by Figure 9 (see data in Supplementary Material A in Supplementary Material available online at http://dx.doi.org/ $10.1155 / 2016 / 2548967)$. The equivalent resistance ranged from $5 \mathrm{kN}$ to $62.5 \mathrm{kN}$, which agrees with the tractive force scope in Figure 2.

According to our previous research [3], Table 3 shows the simulative parameters of the 1804 hybrid drivetrain, which acts as the controlled object.

Based on mass experimental data, Zhou et al. presented the theoretical models used to predict theoretical tractive performance of a wheeled tractor [18]. According to this model, the slip rate, $\delta$, can be calculated by the following equation:

$$
\delta=\delta^{*} \operatorname{Ln} \frac{\phi_{\max }}{\phi_{\max }-L F_{\mathrm{TN}} /\left(a G+h_{\mathrm{T}} F_{\mathrm{TN}}\right)} .
$$

In (24), $\delta^{*}$ and $\phi_{\max }$ are fitting coefficients whose values are recommended as 0.0757 and 0.624 under the common soil conditions of the Northeast China region. The relationship between $\eta_{\delta}$ and $\delta$ is $\eta_{\delta}=1-\delta$. The slip efficiency used in the simulation is established in Figure 10.

In the simulation of plowing, the clutch between GT and PTO is separated. Therefore, the mechanical loss of
TABLE 2: Plowing parameters.

\begin{tabular}{llll}
\hline Number & $Z$ & $b_{1}$ & $h_{\mathrm{k}}$ \\
\hline 0 & 7 & 35 & 30 \\
1 & 6 & 35 & 30 \\
2 & 5 & 32 & 25 \\
3 & 4 & 35 & 25 \\
4 & 4 & 40 & 31 \\
5 & 3 & 30 & 20 \\
6 & 3 & 35 & 22 \\
7 & 1 & 50 & 20 \\
\hline
\end{tabular}

TABLE 3: Simulative parameters of the electric drivetrain.

\begin{tabular}{|c|c|c|}
\hline Part & Parameter name & Value and unit \\
\hline \multirow{8}{*}{ Vehicle } & Overall length & $5.2 \mathrm{~m}$ \\
\hline & Overall width & $2.69 \mathrm{~m}$ \\
\hline & Overall height & $2.97 \mathrm{~m}$ \\
\hline & $L$ & $2.85 \mathrm{~m}$ \\
\hline & $h_{\mathrm{T}}$ & $1.6 \mathrm{~m}$ \\
\hline & G & $112.64 \mathrm{kN}$ \\
\hline & $r_{\mathrm{TN}}$ & $0.9 \mathrm{~m}$ \\
\hline & $a$ & $1.97 \mathrm{~m}$ \\
\hline \multirow{5}{*}{ GT } & Heavy load gear ratio & 5.38 \\
\hline & Moderate load gear ratio & 3.88 \\
\hline & Light load gear ratio & 2.63 \\
\hline & Transport gear ratio & 1.65 \\
\hline & $\eta_{\mathrm{g}}$ & $96.04 \%$ \\
\hline \multirow{15}{*}{ EM } & Voltage rating & $380 \mathrm{~V}$ \\
\hline & Peak voltage & $540 \mathrm{~V}$ \\
\hline & Torque rating & $4138 \mathrm{~N} \cdot \mathrm{m}$ \\
\hline & Rotate speed rating & $300 \mathrm{r} / \mathrm{min}$ \\
\hline & Reduction ratio & 23 \\
\hline & $P_{\mathrm{r}}$ & $130 \mathrm{~kW}$ \\
\hline & $R_{\mathrm{s}}$ & $0.04 \Omega$ \\
\hline & $J$ & $0.0001 \mathrm{~kg} \cdot \mathrm{m}^{2}$ \\
\hline & $V$ & $0.0368 \mathrm{~N} \cdot \mathrm{m} \cdot \mathrm{min} / \mathrm{r}$ \\
\hline & $k_{\mathrm{c}}$ & $0.15 \mathrm{~kW} / \mathrm{N}^{2} \cdot \mathrm{m}^{2}$ \\
\hline & $k_{\mathrm{i}}$ & $0.1 \mathrm{~kW} \cdot \mathrm{min} / \mathrm{r}$ \\
\hline & $k_{\mathrm{w}}$ & $1.2 e-7 \mathrm{~kW} \cdot \mathrm{min}^{3} / \mathrm{r}^{3}$ \\
\hline & $k_{E}^{\prime \prime}$ & $0.0543 \mathrm{~V} \cdot \mathrm{min} / \mathrm{r}$ \\
\hline & $k_{T}^{L}$ & $0.5186 \mathrm{~N} \cdot \mathrm{m} / \mathrm{A}$ \\
\hline & C & $0.21 \mathrm{~kW}$ \\
\hline \multirow{2}{*}{ MD } & $i_{0}$ & 3.2 \\
\hline & $\eta_{0}$ & $98 \%$ \\
\hline \multirow{2}{*}{ AP } & $A$ & $54^{\circ}$ \\
\hline & $N$ & 0.15 \\
\hline
\end{tabular}

the agricultural implement (AI) is irrelevant. The rest of the parameters of efficiency are calculated as

$$
\begin{aligned}
& \eta_{\mathrm{c}}=\eta_{0} \eta_{\mathrm{g}}, \\
& \eta_{\mathrm{f}}=\frac{G f}{F_{\mathrm{TN}}} .
\end{aligned}
$$

Accordingly, the transmission efficiency, $\eta_{c}$, is equal to $94.12 \%$, and the rolling efficiency, $\eta_{\mathrm{f}}$, is dynamically equal to $11.2 / F_{\mathrm{TN}}$.

Based on (22) and (23), $\varepsilon_{\mathrm{d}}$ and $\varepsilon_{\mathrm{dr}}$ of the load torque controller are, respectively, assigned as 44.8 and 35.86 . 


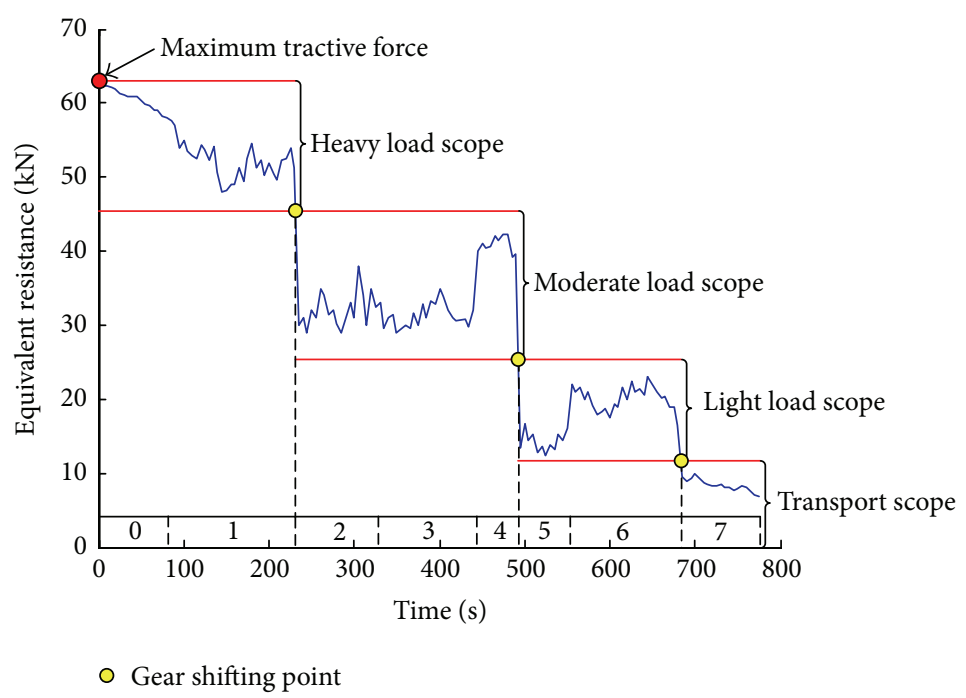

Figure 9: Tractive force of the simulation. Note: numbering 0-7 corresponds to the numbers of plowing parameters in Table 2.

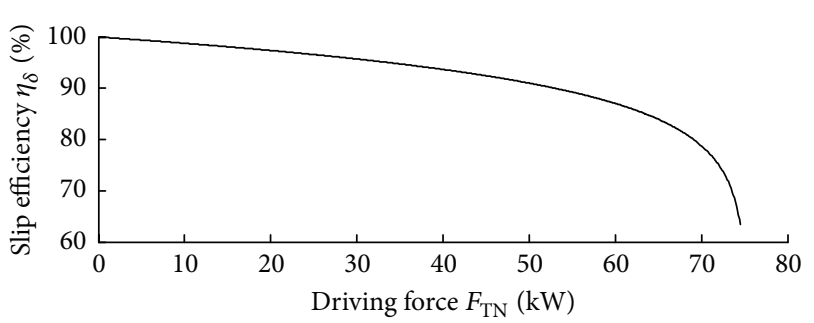

FIGURE 10: Slip efficiency in the simulation.

In the simulation, the tractor working system is simplified as a longitudinal model, which tills in a straight line, and all the side forces can be disregarded. A driver response time to the peak force is set as $0.1 \mathrm{~s}$. It is assumed that the driver can accurately adjust the AP depth in accordance with the load force change. The sampling step length is $5 \mathrm{~s}$. The load force fluctuation owed to the AI and gear switching is ignored.

4.2. PSO Setting in the Simulation. In the simulation, the PSO searching process runs on the platform developed by Birge [19]. Shi and Eberhart researched the set of inertia weights by the simulation on the benchmark problems and found that inertia weight starting with a value from 0.9 to 0.4 through the course of the run greatly improved the performance of PSO [20]. Thus, the start weight value selected here is 0.9 and the end weight value is 0.4 .

The determination of maximum velocity $V_{i \max }, c_{1}$, and $c_{2}$ is mainly based on the formula presented by Zhang et al. as follows [21]:

$$
\begin{aligned}
V_{i \max } & =\lambda X_{i \max }, \\
c_{1} & =c_{2}=\frac{\varphi}{2} .
\end{aligned}
$$

In this case, the searching space of PSO is 2-dimensional and the objective function, (14), is unimodal. Therefore, it is recommended that $\lambda$ is equal to 0.05 and $\varphi$ is set as 4.1 .
As stated earlier, the PSO is searching for the best working point in constraint $\left[T_{\mathrm{L}}, T_{\mathrm{L}}+Q\right]$. The adjustment torque $Q$ is set as $0.5 \mathrm{kN}$ for the purpose of promoting of the search accuracy. In addition, in order to prevent the mechanical power of the searched working point from exceeding the rating power of the EM, the rotate speed of the EM should be bounded by the range, $X_{2 \max }$. Thus, $X_{i \max }$ is described by

$$
\begin{aligned}
& X_{1 \max }=R_{T}=\left(T_{\mathrm{L}}, T_{\mathrm{L}}+0.5\right), \\
& X_{2 \max }=R_{\mathrm{MAV}}=\left(0, \frac{9550 P_{\mathrm{r}}}{T_{\mathrm{L}}}\right) .
\end{aligned}
$$

In every control step, the value of $T_{\mathrm{L}}$ is dependent upon (21).

Shi and Eberhart advised that probably the most common population sizes of PSO are from 20 to 50 [20]. Experimental verification has found that there is no visible difference in searching results when the population size is, respectively, set as $20,30,40$, and 50 . To simplify, we set the population size at 20 .

4.3. Analysis of the Simulation Result. Figure 11 depicts the searching result when the tractive force is $55 \mathrm{kN}$ (which belongs to the heavy load scope). After 38 evolutions, the population fitness degree becomes stable. The best working point is searched as $256.339 \mathrm{r} / \mathrm{min}, 3676.97 \mathrm{~N} \cdot \mathrm{m}$, and the electric energy conversion efficiency is $92.38 \%$.

Figure 12 depicts the searching result when the load torque is $14 \mathrm{kN}$ (which belongs to the light load scope). After 20 evolutions, the population fitness degree becomes stable. The best working point was searched as $218.8 \mathrm{r} / \mathrm{min}$, $2864 \mathrm{~N} \cdot \mathrm{m}$, and the electric energy conversion efficiency was $92.83 \%$. The searching results on two situations show that the LTCS makes the result of PSO searching self-adaptive for the tractive force. In addition, the convergent evolution times testify that the set of PSO parameters make the searching process sufficiently rapid. 

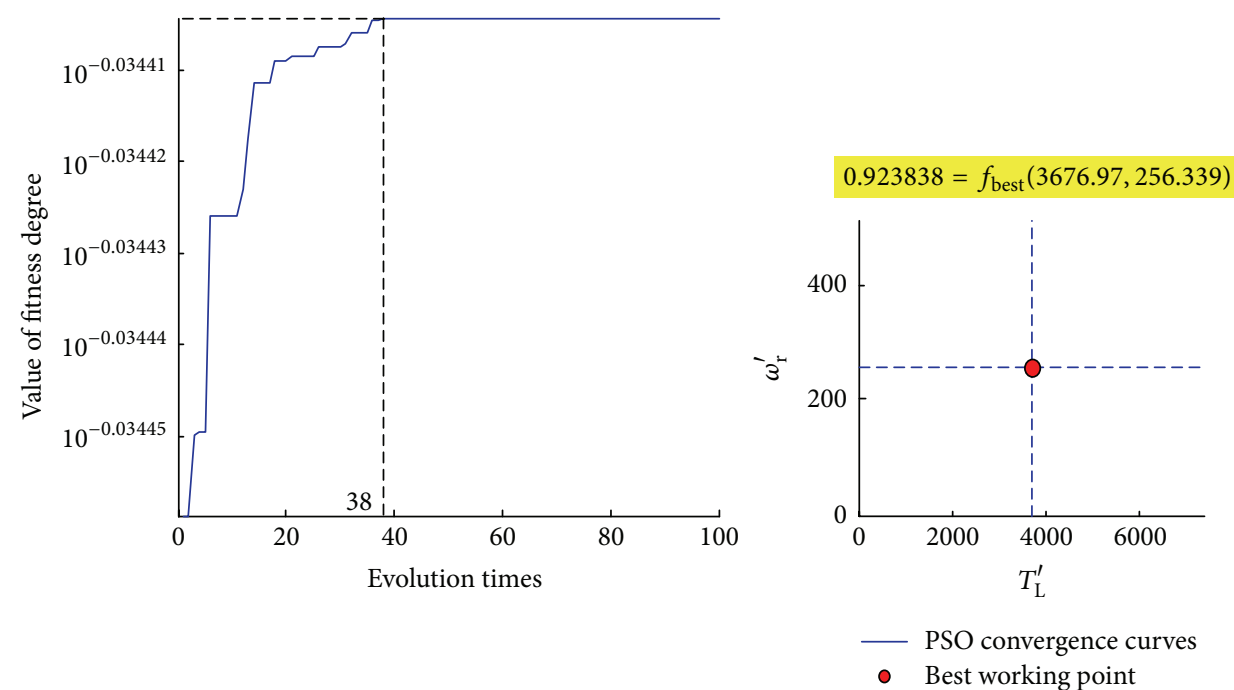

FIGURE 11: PSO searching on the heavy load situation.
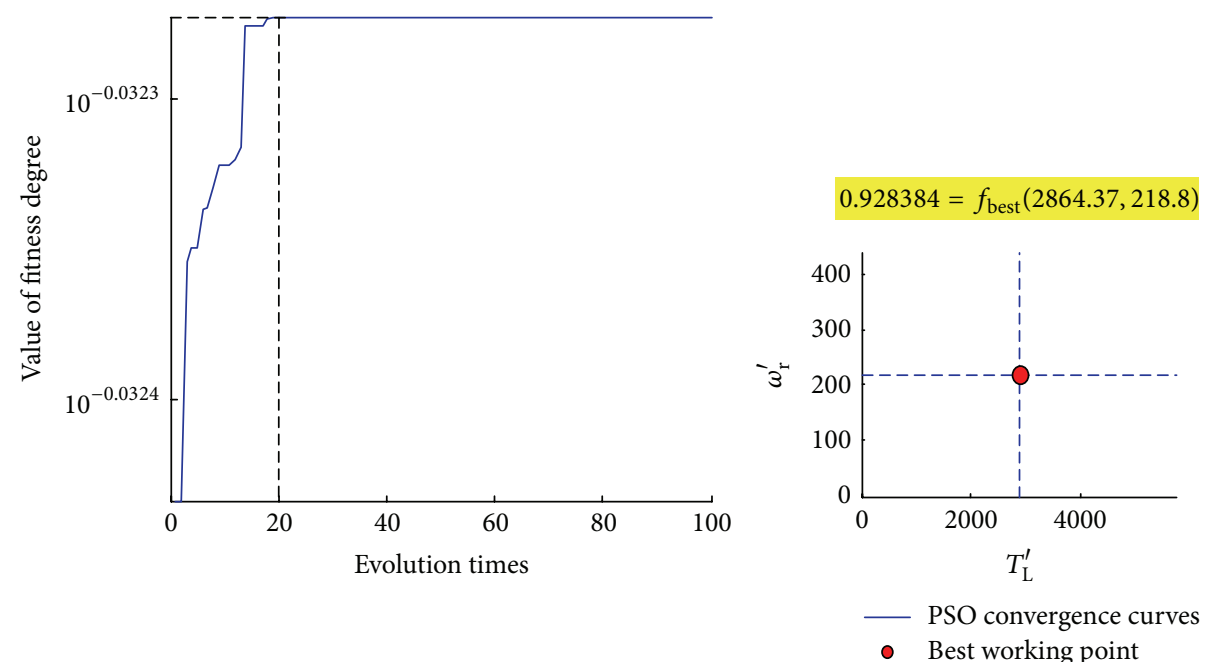

FIGURE 12: PSO searching on the light load situation.

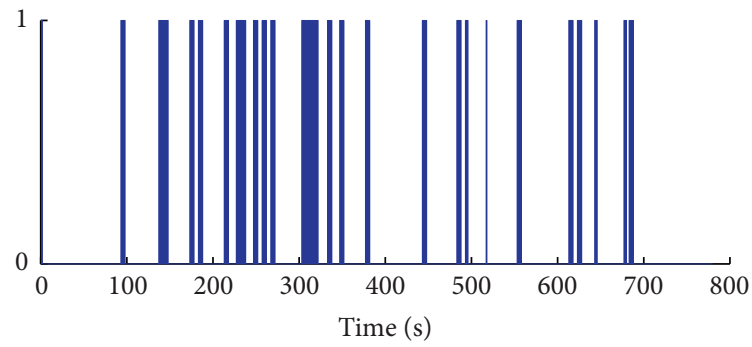

Figure 13: Output of load torque controller in the simulation.

The control single of the load torque controller in the simulation is expressed by Figure 13. In comparison with Figure 9, when the hybrid works with heavy, moderate, and light load gear, initialization signals can frequently be activated by strong fluctuations in the load force. After $680 \mathrm{~s}$, when the load force begins to meet the transport condition with a relatively stable load force, there is no signal output. In conclusion, the rules of the load torque controller can judge the load force with acceptable accuracy and adaptivity. The initialization signals' superposition process during the simulation is described in Supplementary Material B.

Figure 14 depicts the simulative results of the voltagecurrent performance controlled by LTCS. According to the discussion of Figure 4, the current, $I_{\mathrm{s}}$, is defined as $T_{\mathrm{L}}^{\prime}$, which follows the relationship of (4). And the rotate speed of EM, $\omega_{\mathrm{r}}$, is adjusted by changing the voltage.

The load torque followed control method (LTFC) is used popularly in the BLDC control of the electric tractor. According to the excepted torque, LTFC controls the mechanical output of the EM by adjusting the phase current [12]. Compared with another electric vehicle electric motor control strategy, the speed followed control method (which controls the BLDC with expected speed); according to the discussion in Figure 2, 


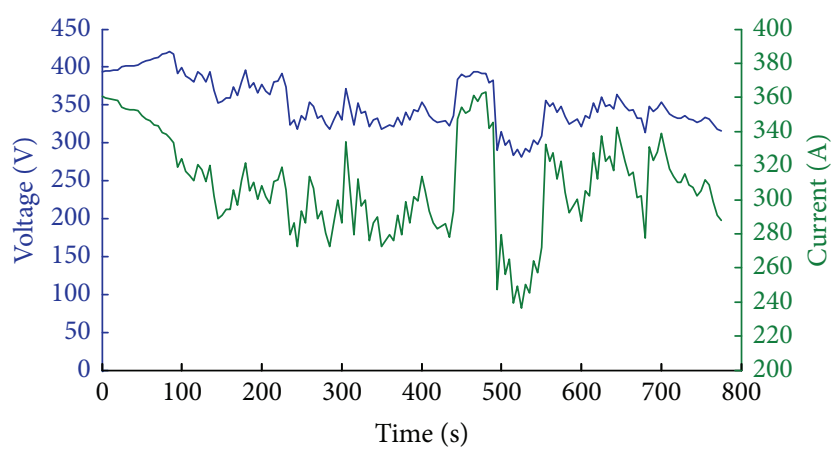

FIGURE 14: The electrical characteristic controlled in the simulation.

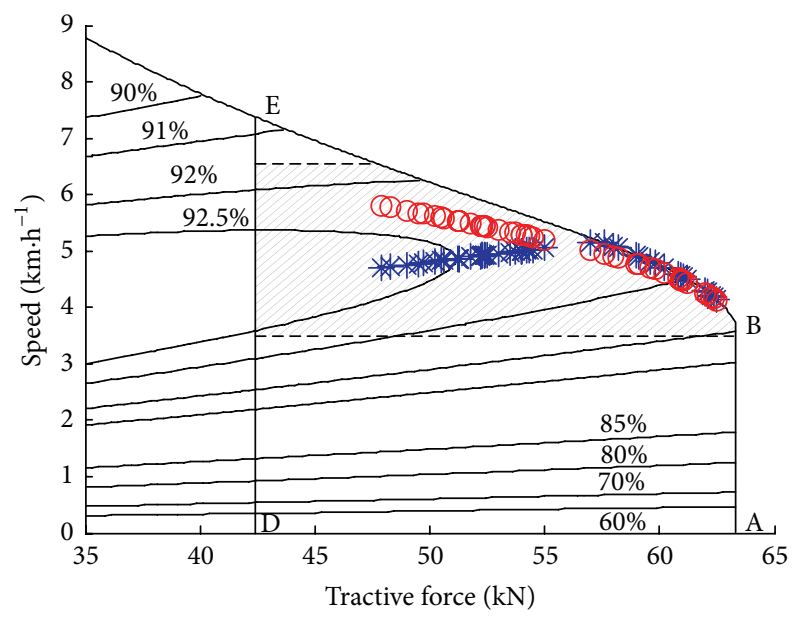

(ㅇ) Electric energy conversion efficiency of EM

- - - Ploughing speed scope

* Working point controlled by LTCS

Working point controlled by LTFC

FIGURE 15: Working points distribution of the high load gear.

LTFC is more suitable for the farming working conditions, which have high-level load force. Thus, we selected the LTFC as the comparison for analyzing the control performance of LTCS.

Figure 15 depicts the drivetrain working points of LTCS when the tractor works with heavy loads. The figure shows that some of working points are distributed on the edge of the speed-traction force performance curve, and others are in the central area near $92.5 \%$. Both of the two distributions are near the best efficiency area under an equivalent traction force. The speed range of working points is $4.1 \mathrm{~km} / \mathrm{h} \sim 5.8 \mathrm{~km} / \mathrm{h}$, which can meet the speed scope of plowing.

By comparing the heavy load control performance of LTCS and LTFC in Figure 15, all of the working points of both control strategies can meet the speed requirement of plowing, but the working points of LTCS present more efficient energy conversion.

Figure 16 depicts the drivetrain working points when the tractor works with moderate load. The energy conversion efficiency of the working points controlled by LTCS exceeds

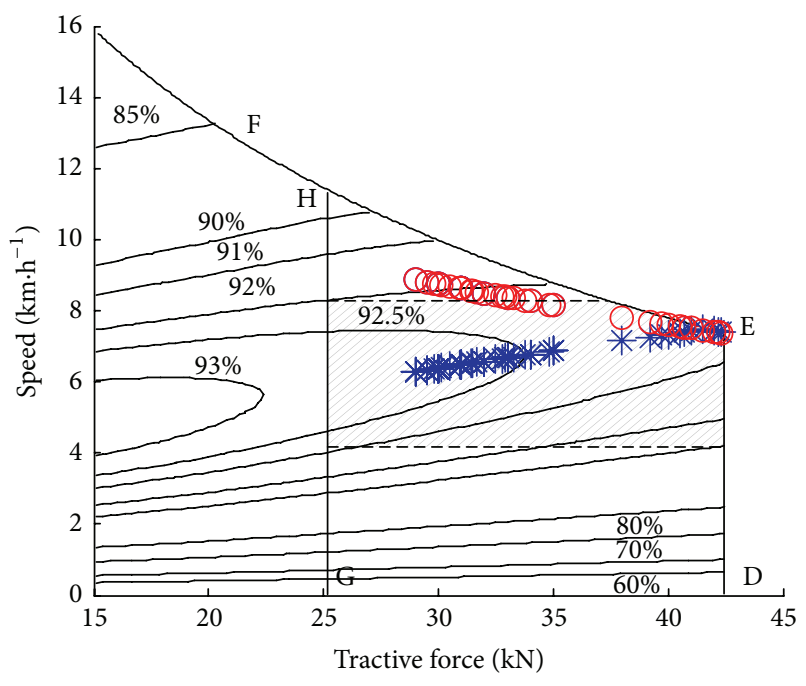

(요 Electric energy conversion efficiency of EM

--- Cultivating and hoeing speed scope

* Working point controlled by LTCS

Working point controlled by LTFC

FIGURE 16: Working points distribution of moderate load gear.

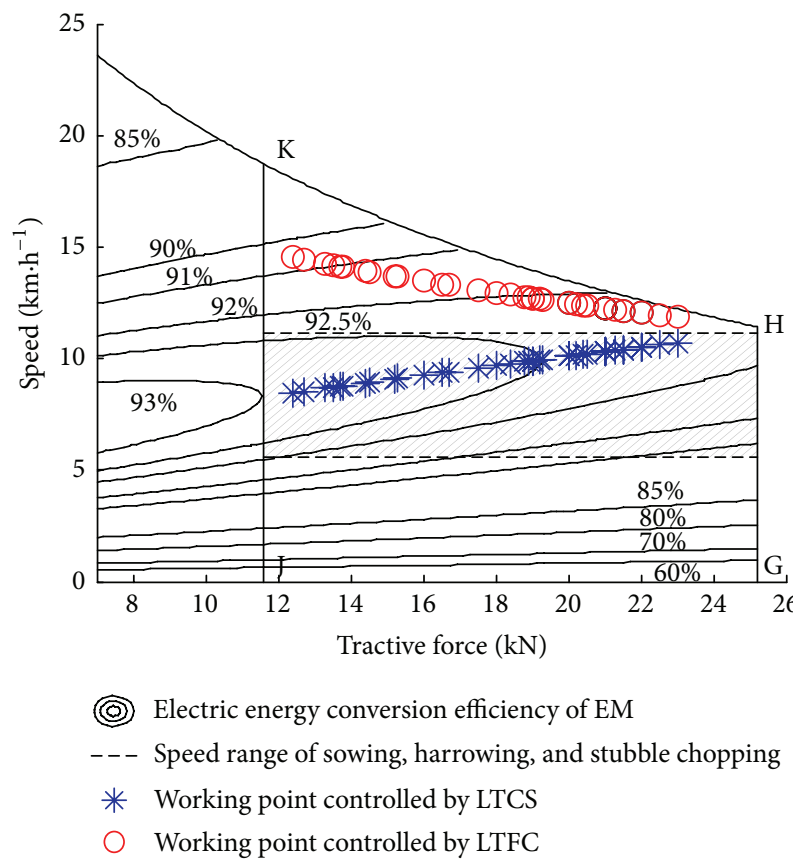

FIGURE 17: Working points distribution of light load gear.

$92.1 \%$. When the traction force is less than $33.3 \mathrm{kN}$, the efficiency can be greater than $92.5 \%$. In addition, the speed range is $5.1 \mathrm{~km} / \mathrm{h} \sim 7.4 \mathrm{~km} / \mathrm{h}$, which meets the speed requirement of cultivating and hoeing. Compared with the case of LTFC, LTCS presents more efficient speed and control performance.

Figure 17 depicts the working points' distribution when the tractor works with a light load. As shown, the energy conversion efficiency of EM controlled by LTCS is almost 


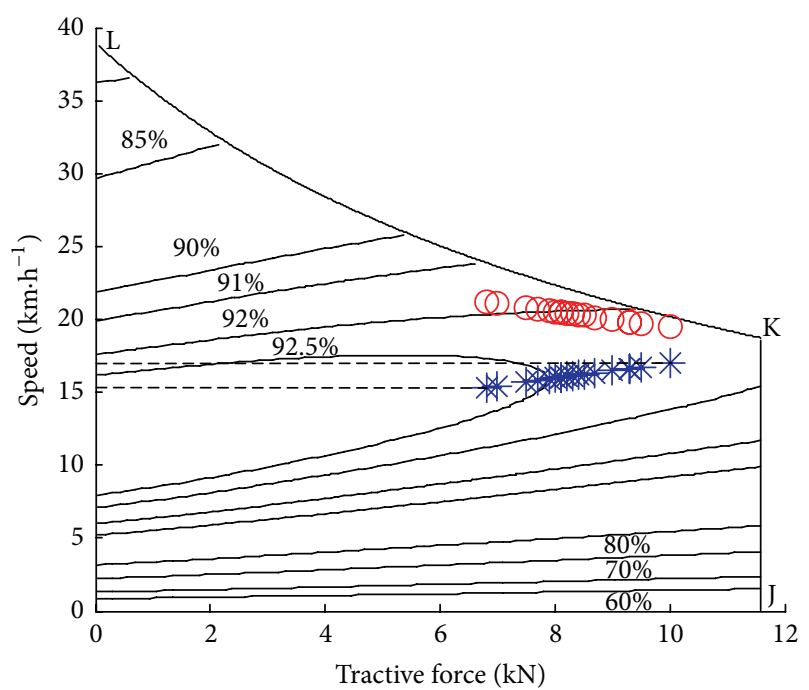

(C) Electric energy conversion efficiency of EM

* Working point controlled by LTCS

Working point controlled by LTFC

FIGURE 18: Working points distribution of transport gear.

always superior. The speed range is $8.5 \mathrm{~km} / \mathrm{h} \sim 10.7 \mathrm{~km} / \mathrm{h}$, which can meet the speed scope of sowing, harrowing, and stubble chopping. In addition, the maximum speed change rate is $0.2 \mathrm{~km} / \mathrm{kN} \cdot \mathrm{h}$, which can enhance the seeding uniformity.

By contrast, the speeds of all of the working points controlled by LTFC are higher than the speed range of sowing, harrowing, and stubble chopping. This is because when the tractor is working with AI, the rotate speed of PTO is commonly changeless. In the 1804 series hybrid electric tractor, the rotate speed is $1000 \mathrm{r} / \mathrm{min}$ or $540 \mathrm{r} / \mathrm{min}$. When the tractor speed exceeds the speed scope of its farming type, the farming quality may be decreased (e.g., for the sowing, a faster tractor speed means longer seed spacing, which will reduce the seeding rate and consequently decrease the crop production). Therefore, LTFC is not suitable for the light working conditions of electric tractor.

Figure 18 shows the distribution of working points when LTCS is used for the transport condition. Although the efficiencies of all of the working points can be approximated to the maximum under an equivalent traction force, the speed is relatively slow for transporting, which may reduce the conveying efficiency. Furthermore, when the 1804 hybrid transports out of the farm, the control result cannot attain adequate traffic security and drive flexibility, which means LTCS is not appropriate for the road transport condition.

In the design of LTCS, load torque is used as the independent variable of target function, and the enclosure space based on load torque is the only constraint of the PSO search. Consequently, the speed changes dependent on the status of the load force, and that is why the speed cannot be adjusted independently and intentionally.

Simulation results of energy conversion efficiency are depicted in Figure 19. In each simulation, the electric tractor

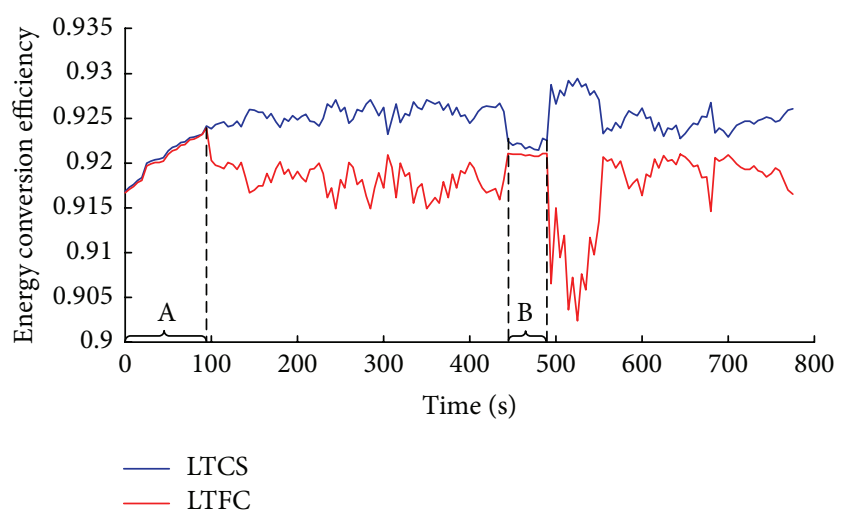

Figure 19: The comparison of energy conversion efficiency under the control of LTCS and LTFC.

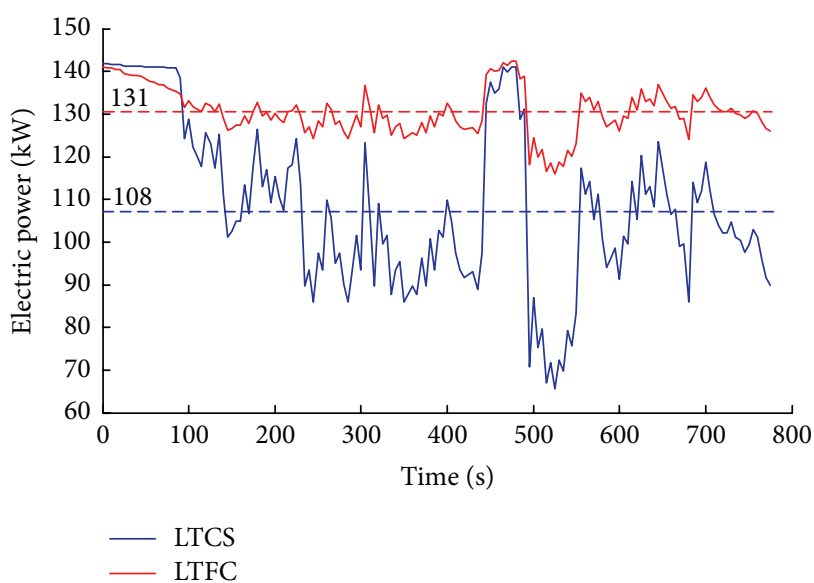

FIGURE 20: The comparison of ES power consumption under the control of LTCS and LTFC.

controlled by LTCS is more efficient than when controlled by LTFC in electric use. In addition, its mean energy conversion efficiency is $92.46 \%$, and there are small improvements in regions $\mathrm{A}$ and $\mathrm{B}$. The reason for this is that further improvement of energy conversion efficiency is limited by the rating power of electric motor, which proves that the set of PSO searching ranges are appropriate.

Figure 20 depicts the electric power consumption of the ES. Due to the improvement of the EM energy conversion efficiency and the speed-limited function of LTCS, the mean electric power consumption can reduce by $23 \mathrm{~kW}$, and the energy-saving effect of farming work can increase by $21.3 \%$ in comparison with the LTFC.

In summary, when LTCS is used for working the farm, the electric tractor possesses superior agricultural adaptation and an obvious energy-saving effect. In off-road conditions, the electric tractor can also be engaged in some transport operations where speed performance is not required. In the future, when the LTCS is used in a realistic environment, the following is recommended:

(1) The objective function should be further amended by considering the change of temperature or be built by experimental method. 
(2) The mechanical dynamic characteristics of the motor output shaft should be controlled by the PSO method presented by Elwer et al. [10].

(3) The control parameters of PSO should be optimized by considering the hardware performance of the electric control unit selected; the principle is based on the premise of appropriate precision, so the convergence rate should be increased to the maximum speed.

\section{Conclusion}

In this paper, the load torque based control strategy used for maintaining high energy conversion efficiency of the traction motor in an electric tractor is presented and studied. The control process contains a PSO search that seeks the best working point with maximum energy conversion efficiency and initiation control and whose target is to adjust the searching results dynamically based on peak torque. First, by the mathematical modeling, the relation between the mechanical characteristic and energy conversion is established, and then the target function is performed. Second, by analyzing the speed-traction force performance of the 1804 hybrid, the load torque is selected as the constraint of the PSO search. By describing the schematic representation and the internal task action, the control method and flow are obtained. By making logic and fuzzy rules, the torque controller based on driver intention was designed. Finally, after the working condition collection, which covers most of the tillage force, simulation of traction experiment is conducted. The distribution of initialization signal output from the load torque controller fits the load force fluctuation, which means the initialization control can be self-adaptive to the working condition, and the search results can be time-sensitive. Compared with LTFC, LTCS maintains the energy conversion efficiency of the EM near the maximum during the simulation time. Meanwhile, the working speed is sufficiently stable for the requirement of agriculture uniformity and suitable for the speed scope of tillage.

\section{Nomenclature}

A: $\quad$ Maximum opening angle of $\mathrm{AP}\left({ }^{\circ}\right)$

a: $\quad$ Distance from barycenter to front axle $(\mathrm{m})$

B: $\quad$ Depth of AP $\left(^{\circ}\right)$

$b_{1}$ : Width of single ploughshare $(\mathrm{cm})$

C: $\quad$ Constant loss of EM (kW)

$c_{1}, c_{2}: \quad$ Acceleration factors (-)

$e_{\mathrm{a}}, e_{\mathrm{b}}, e_{\mathrm{c}}$ : Per phase back EMF (V)

$e_{\mathrm{s}}$ : $\quad$ Back electromotive force $(\mathrm{V})$

$F_{\text {Af }}: \quad$ Air resistance $(\mathrm{kN})$

$F_{\mathrm{f}}$ : $\quad$ Rolling resistance $(\mathrm{kN})$

$F_{\mathrm{g}}$ : $\quad$ Plowing resistance $(\mathrm{kN})$

$F_{\mathrm{i}}$ : $\quad$ Acceleration resistance $(\mathrm{kN})$

$F_{\mathrm{p}}: \quad$ Slope resistance $(\mathrm{kN})$

$F_{\mathrm{T}}: \quad$ Tractive force $(\mathrm{kN})$

$F_{\mathrm{TN}}$ : Driving force $(\mathrm{kN})$

$f: \quad$ Rolling resistance coefficient (-)

G: $\quad$ Tractor gravity $(\mathrm{kN})$ $h_{\mathrm{k}}: \quad$ Plowing depth $(\mathrm{cm})$

$h_{\mathrm{T}}: \quad$ Hitch point height $(\mathrm{m})$

$I_{\mathrm{a}}, I_{\mathrm{b}}, I_{\mathrm{c}}: \quad$ Per phase current (A)

$I_{\mathrm{s}}: \quad$ Winding current $(\mathrm{A})$

$i_{\mathrm{a}}: \quad$ Gear ratio of AI (-)

$i_{\mathrm{g}}: \quad$ Gear ratio of GT (-)

$i_{\mathrm{g}}^{\prime}$ :

$i_{0}:$

$J:$

Gear ratio between EM and PTO (-)

Gear ratio of MD (-)

Rotational inertia of drivetrain $\left(\mathrm{kg} \cdot \mathrm{m}^{2}\right)$

$k: \quad$ Soil specific resistance $\left(\mathrm{kN} / \mathrm{cm}^{2}\right)$

$k_{E}: \quad$ Back EMF constant $(\mathrm{V} \cdot \mathrm{min} / \mathrm{r})$

$k_{T}: \quad$ Torque constant $(\mathrm{N} \cdot \mathrm{m} / \mathrm{A})$

$k_{\mathrm{c}}: \quad$ Copper loss coefficient $\left(\mathrm{kW} / \mathrm{N}^{2} \cdot \mathrm{m}^{2}\right)$

$k_{\mathrm{i}}$ : $\quad$ Iron loss coefficient $(\mathrm{kW} \cdot \mathrm{min} / \mathrm{r})$

$k_{\mathrm{w}}$ : $\quad$ Air resistance coefficient $\left(\mathrm{kW} \cdot \mathrm{min}^{3} / \mathrm{r}^{3}\right)$

$L: \quad$ Wheelbase $(\mathrm{m})$

$L_{\mathrm{a}}, L_{\mathrm{b}}, L_{\mathrm{c}}:$ Per phase self-inductance $(\mathrm{H})$

$L_{\mathrm{m}}: \quad$ Mutual inductance $(\mathrm{H})$

$L_{\mathrm{n}}$ : $\quad$ Self-inductance $(\mathrm{H})$

$L_{\mathrm{s}}: \quad$ Leakage inductance $(\mathrm{H})$

$N: \quad$ Free travel ratio of AP (-)

$P_{\mathrm{c}}: \quad$ Copper loss $(\mathrm{kW})$

$P_{\mathrm{i}}: \quad$ Icon loss $(\mathrm{kW})$

$P_{\text {in }}: \quad$ Electric power input of EM $(\mathrm{kW})$

$P_{\mathrm{M}}: \quad$ Mechanical loss $(\mathrm{kW})$

$P_{\text {out }}: \quad$ Mechanical power output of EM (kW)

$P_{\mathrm{r}}: \quad$ Rating power of EM (kW)

$R_{\mathrm{MAV}}$ : $\quad$ Searching range of rotate speed ( $\mathrm{r} / \mathrm{min}$ )

$R_{\mathrm{s}}: \quad$ Stator winding resistance $(\Omega)$

$R_{T}$ : Searching range of torque $(\mathrm{N} \cdot \mathrm{m})$

$r_{\mathrm{TN}}$ : Rolling radius of drive wheel $(\mathrm{m})$

$T_{\mathrm{e}}: \quad$ Electromagnetic torque $(\mathrm{N} \cdot \mathrm{m})$

$T_{\mathrm{L}}: \quad$ Load torque of EM $(\mathrm{N} \cdot \mathrm{m})$

$T_{\max }: \quad$ Maximum torque of EM $(\mathrm{N} \cdot \mathrm{m})$

$T_{\mathrm{TN}}$ : Torque output of driving wheel $(\mathrm{N} \cdot \mathrm{m})$

$T_{\mathrm{w}}$ : $\quad$ Torque output of AI $(\mathrm{N} \cdot \mathrm{m})$

$t_{\mathrm{r}}: \quad$ AP release time (s)

$U_{\mathrm{a}}, U_{\mathrm{b}}, U_{\mathrm{c}}$ : Per phase voltage $(\mathrm{V})$

$U_{\mathrm{t}}: \quad$ Input voltage $(\mathrm{V})$

$V: \quad$ Viscous resistance coefficient $(\mathrm{N} \cdot \mathrm{m} \cdot \mathrm{min} / \mathrm{r})$

$v: \quad$ Tractor speed $(\mathrm{km} / \mathrm{h})$

$Z: \quad$ Number of ploughshares (-)

$\omega_{\mathrm{r}}: \quad$ Rotate speed of EM ( $\left.\mathrm{r} / \mathrm{min}\right)$

$\omega_{\mathrm{TN}}$ : $\quad$ Rotate speed of driving wheel $(\mathrm{r} / \mathrm{min})$

$\omega_{\mathrm{w}}: \quad$ Rotate speed of AI ( $\left.\mathrm{r} / \mathrm{min}\right)$

$\eta_{\mathrm{a}}$ : $\quad$ Mechanical efficiency of AI (\%)

$\eta_{\mathrm{c}}: \quad$ Transmission efficiency (\%)

$\eta_{\mathrm{f}}: \quad$ Rolling efficiency (\%)

$\eta_{\mathrm{g}}: \quad$ Mechanical efficiency of GT (\%)

$\eta_{\mathrm{g}}^{\prime}$ : $\quad$ Mechanical efficiency between EM and PTO (\%)

$\eta_{\mathrm{m}}: \quad$ Electric conversion energy efficiency of EM (\%)

$\eta_{\mathrm{T}}: \quad$ Tractive efficiency $(\%)$

$\eta_{\delta}: \quad$ Slip efficiency (\%)

$\eta_{0}$ : $\quad$ Mechanical efficiency of MD (\%)

$\varepsilon: \quad$ Inertia weight (-)

$\varepsilon_{\mathrm{d}}$ : $\quad$ Quantization factor of footplate depth (-) 
$\varepsilon_{\mathrm{dr}}:$ Footplate deepening rate quantization factor (-)

$\gamma: \quad$ Number of iterations (-)

$\delta: \quad$ Slip rate (-).

\section{Abbreviations}

AI: Agricultural implement

AP: Accelerator pedal

BLDC: Brushless direct current motor

EM: Electric motor

EMF: Electromotive force

ES: Energy system

GT: Gearbox transmission

ICE: Internal combustion engine

LTCS: Load torque control strategy

LTFC: Load torque followed control method

MC: $\quad$ Motor controller

MD: Main drive

PSO: Particle swarm optimization algorithm

PTO: Power take-off shaft.

\section{Competing Interests}

The authors declare that there are no competing interests regarding the publication of this paper.

\section{Acknowledgments}

The authors would like to thank the YTO Group Corporation for the study permission and technical support. The project is supported by National Natural Science Foundation of China (no. 51375145), Science and Technique Foundation of Henan Province (Grant no. 142102210424), and Research Program of Application Foundation and Advanced Technology of Henan Province (no. 152300410080). The authors thank Accdon for its linguistic assistance during the preparation of this paper.

\section{References}

[1] M. Carlini, R. I. Abenavoli, H. Kormanski, and K. Rudzinska, "Hybrid electric propulsion system for a forest vehicle," in Proceedings of the 32nd Intersociety Energy Conversion Engineering Conference, vol. 3, pp. 2019-2023, Honolulu, Hawaii, USA, August 1997.

[2] S. Florentsev, D. Izosimov, L. Makarov, S. Baida, and A. Belousov, "Complete traction electric equipment sets of electromechanical drive trains for tractors," in Proceedings of the IEEE Region 8 International Conference on Computational Technologies in Electrical and Electronics Engineering (SIBIRCON '10), pp. 611-616, IEEE, Irkutsk, Russia, July 2010.

[3] L. Xu, M. Liu, and Z. Zhou, "Design of drive system for series hybrid electric tractor," Transactions of the Chinese Society of Agricultural Engineering, vol. 30, no. 9, pp. 11-18, 2014.

[4] J. Wong, Terramechanics and Off-Road Vehicle Engineering: Terrain Behaviour, Off-Road Vehicle Performance and Design, Elsevier, 2nd edition, 2010.

[5] P. Garcia, J. P. Torreglosa, L. M. Fernandez, and F. Jurado, "Control strategies for high-power electric vehicles powered by hydrogen fuel cell, battery and supercapacitor," Expert Systems with Applications, vol. 40, no. 12, pp. 4791-4804, 2013.

[6] M. Sorrentino, G. Rizzo, and I. Arsie, "Analysis of a rule-based control strategy for on-board energy management of series hybrid vehicles," Control Engineering Practice, vol. 19, no. 12, pp. 1433-1441, 2011.

[7] W. Shabbir and S. A. Evangelou, "Real-time control strategy to maximize hybrid electric vehicle powertrain efficiency," Applied Energy, vol. 135, pp. 512-522, 2014.

[8] C. Osornio-Correa, R. Villarreal-Calva, J. Estavillo-Galsworthy, A. Molina-Cristóbal, and S. Santillán-Gutiérrez, "Optimization of power train and control strategy of a hybrid electric vehicle for maximum energy economy," Ingeniería, Investigación $y$ Tecnología, vol. 14, no. 1, pp. 65-80, 2013.

[9] J. Wu, C.-H. Zhang, and N.-X. Cui, "PSO algorithm-based parameter optimization for HEV powertrain and its control strategy," International Journal of Automotive Technology, vol. 9, no. 1, pp. 53-59, 2008.

[10] A. S. Elwer, S. A. Wahsh, M. O. Khalil, and A. M. Nur-Eldeen, "Intelligent fuzzy controller using particle swarm optimization for control of permanent magnet synchronous motor for electric vehicle," in Proceedings of the 29th Annual Conference of the IEEE Industrial Electronics Society, vol. 2, pp. 1762-1766, Roanoke, Va, USA, November 2003.

[11] L. Qian, Z. Gong, and H. Zhao, "Simulation of hybrid electric vehicle control strategy based on fuzzy neural network," Journal of System Simulation, vol. 18, no. 5, pp. 1384-1387, 2006.

[12] M. Ehsani, Y. Gao, and A. Emadi, Modern Electric, Hybrid Electric, and Fuel Cell Vehicle: Fundamentals, Theory, and Design, CRC Press, New York, NY, USA, 2nd edition, 2010.

[13] J. Larminie and J. Lowry, Electric Vehicle Technology Explained, John Wiley \& Sons, New York, NY, USA, 2003.

[14] Y. Rahmat-Samii, "Genetic algorithm (GA) and particle swarm optimization (PSO) in engineering electromagnetics," in Proceedings of the 17th International Conference on Applied Electromagnetics and Communications, pp. 1-5, Dubrovnik, Croatia, October 2003.

[15] G. Tomassetti and L. Cagnina, "Particle swarm algorithms to solve engineering problems: a comparison of performance," Journal of Engineering, vol. 2013, Article ID 435104, 13 pages, 2013.

[16] Q.-N. Wang, X.-Z. Tang, P.-Y. Wang, and L. Sun, "Control strategy of hybrid electric vehicle based on driving intention identification," Journal of Jilin University (Engineering and Technology Edition), vol. 42, no. 4, pp. 789-795, 2012.

[17] D. V. McGehee, E. N. Mazzae, and G. H. S. Baldwin, "Driver reaction time in crash a voidance research: validation of a driving simulator study on a test track," in Proceedings of the 14th Triennial Congress of the International Ergonomics Association and 44th Annual Meeting of the Human Factors and Ergonomics Society, vol. 44, no. 20, pp. 320-323, Santa Monica, Calif, USA, July 2000.

[18] Z. Zhou, Z. Fang, and W. Zhang, "Computer aided analysis on the theoretical tractive characteristics of tractor," Journal of Luoyang Institute of Technology, vol. 14, no. 1, pp. 1-6, 1993.

[19] B. Birge, "PSOt-a particle swarm optimization toolbox for use with matlab," in Proceedings of the IEEE Swarm Intelligence Symposium (SIS '03), pp. 182-186, Indianapolis, Ind, USA, April 2003.

[20] Y. Shi and R. C. Eberhart, "Parameter selection in particle swarm optimization," in Evolutionary Programming VII: 7th 
International Conference, EP98 San Diego, California, USA, March 25-27, 1998 Proceedings, vol. 1447 of Lecture Notes in Computer Science, pp. 591-600, Springer, Berlin, Germany, 1998.

[21] L.-P. Zhang, H.-J. Yu, and S.-X. Hu, "Optimal choice of parameters for particle swarm optimization," Journal of Zhejiang University: Science, vol. 6, no. 6, pp. 528-534, 2005. 


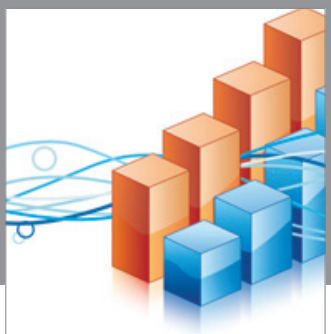

Advances in

Operations Research

vatem alat4

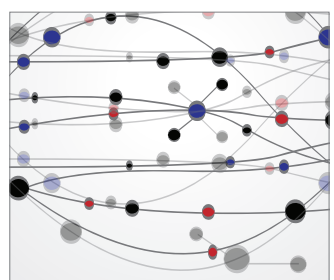

\section{The Scientific} World Journal
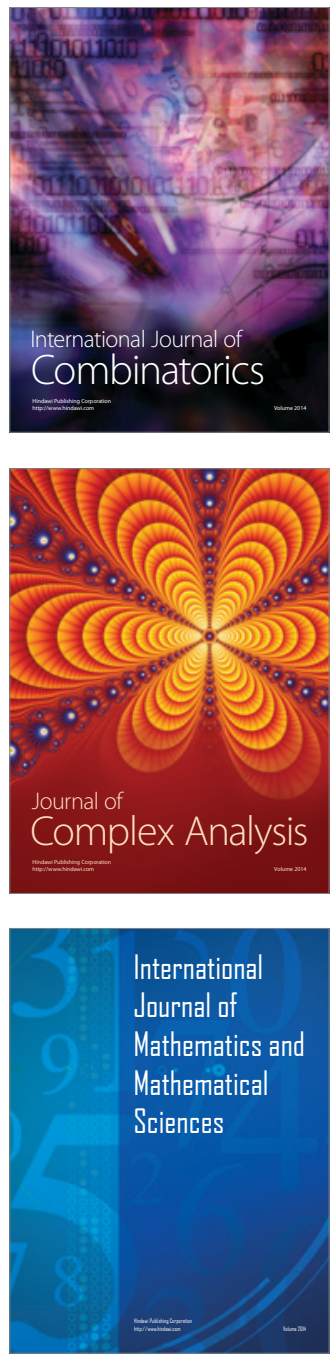
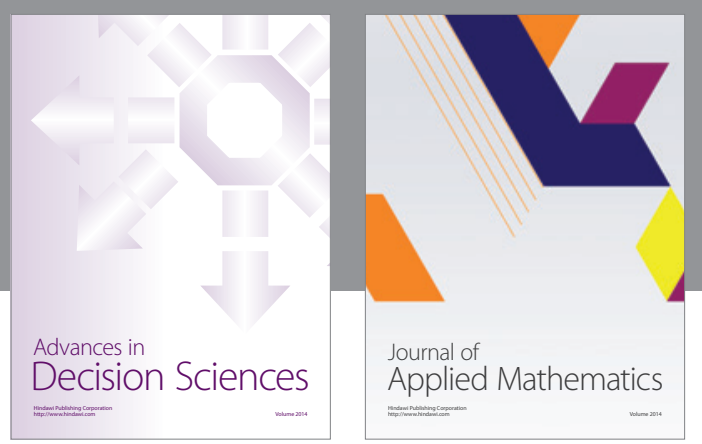

Algebra

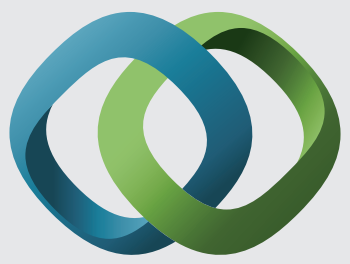

\section{Hindawi}

Submit your manuscripts at

http://www.hindawi.com
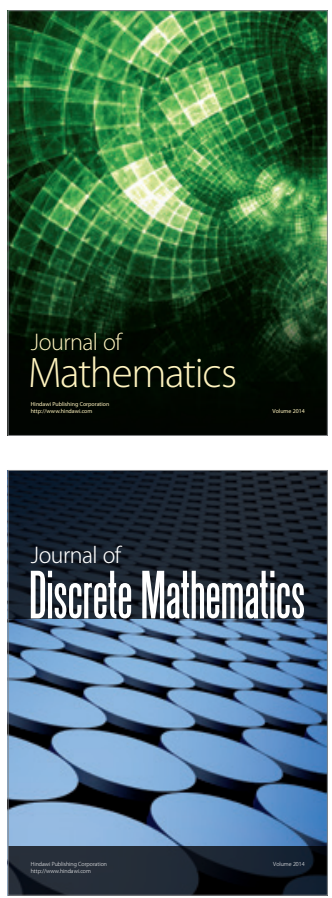

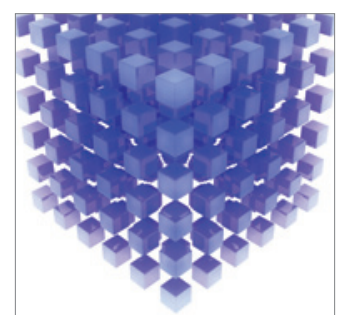

Mathematical Problems in Engineering
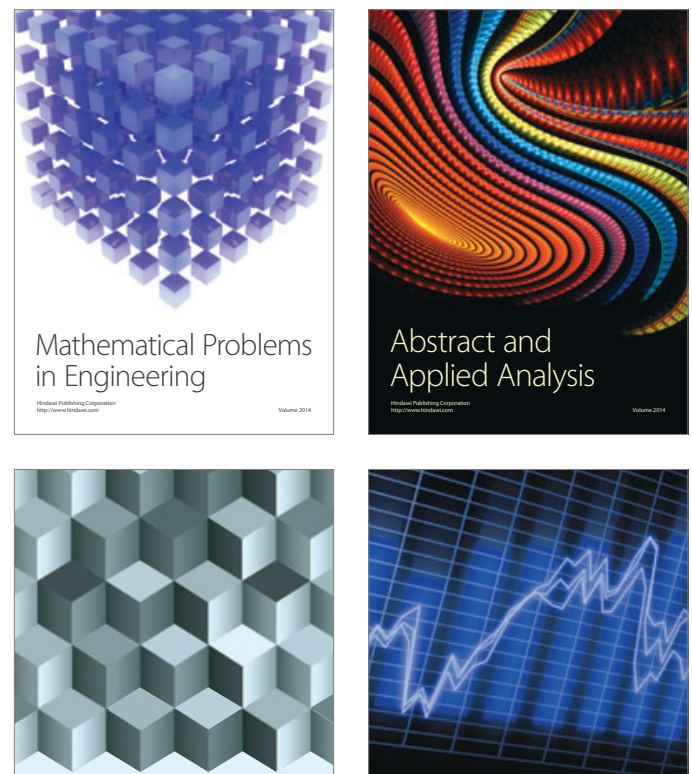

Journal of

Function Spaces

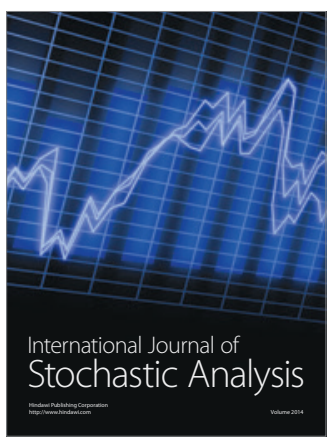

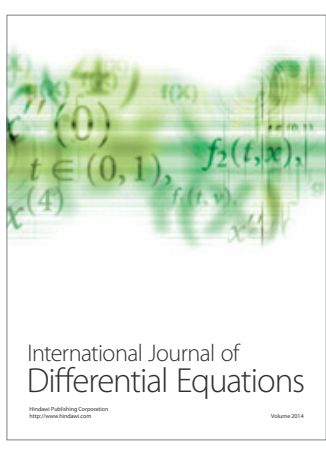
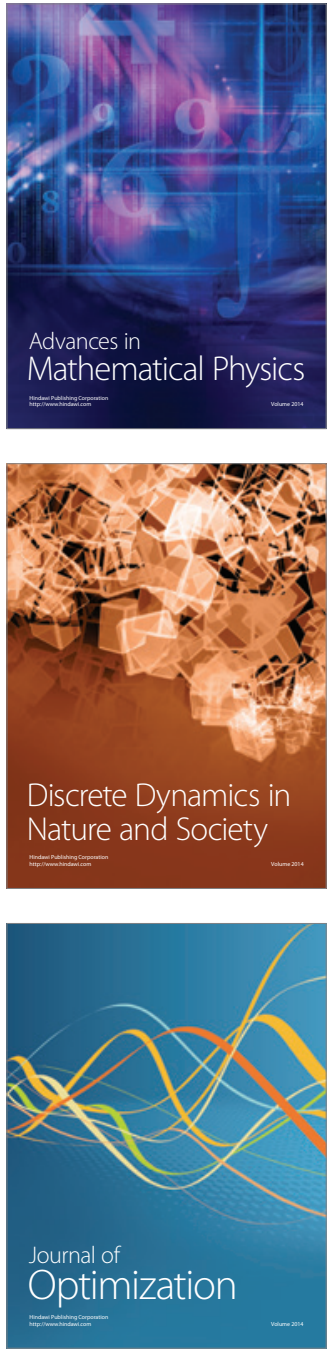